\title{
Diabetic Foot Infections and Outcomes: A Single Center Study
}

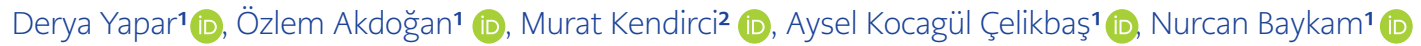 \\ 1 Department of Infectious Diseases and Clinical Microbiology, Hitit University School of Medicine, Çorum, Turkey \\ 2 Department of General Surgery, Hitit University School of Medicine, Çorum, Turkey
}

\begin{abstract}
Objective: Diabetic foot infections (DFI) is one of the most important complications of diabetes mellitus. In this study, we aimed to show the causative microorganisms among patients with DFI and evaluate the long term results.

Materials and Methods: We included the patients over 18 years old who were followed up with DFI, with deep tissue cultures between July 26, 2015, and November 5, 2018, in our center. Demographic data of the patients, Hba1c levels, nasal swab, tissue biopsy and antibiogram results of microorganisms, were evaluated. The outcomes were infection, amputation, and mortality.

Results: In total, 397 patients followed up with DFI diagnosis in "Diabetic Foot and Chronic Wound Unit" were included. The mean age was 65.48 years, and $74.3 \%$ of the patients were male. The most common gram-negative agent was Pseudomonas aeruginosa (37.1\%), and the gram-positive agent was Staphylococcus aureus (56.5\%). A surgical procedure was performed in $57.2 \%$ of the cases. Finger amputation interventions were $33.5 \%$ of the interventions, $36.6 \%$ were surgical debridement, and the remaining $30 \%$ were major amputations. The mortality rate was $1.5 \%$.

Conclusion: Tissue culturing is an important diagnostic tool that gives etiology and susceptibility pattern of bacteria in patients with DFI.

Keywords: Diabetic foot infections, tissue biopsy cultures, diabetes mellitus
\end{abstract}

\section{INTRODUCTION}

D iabetes is a widespread metabolic disease in the world. Diabetic foot, which develops in cases where diabetes control is not provided, is a clinical picture that impairs the quality of life of cases and sometimes leads to undesirable consequences including limb amputation. The global prevalence of diabetic foot is reported to be $25.2-58 \%(1,2,3)$. Infection is one of the most common and serious complications of diabetic foot ulcers, and the duration of hospital stay because of diabetic foot infections (DFI) is much longer than other complications of diabetes (4). Therefore, the appropriateness of empirical antibiotic therapy is essential in DFI. It is impossible to distinguish between bacteria colonizing the skin flora and microorganisms causing infection with
Corresponding Author: Derya Yapar

E-mail: drderyayapar@hotmail.com

Received: July 13, 2021

Accepted: August 24, 2021

Published: August 31, 2021

\section{Suggested citation:}

Yapar D, Akdoğan Ö, Kendirci

M, Çelikbaş-Kocagül A, Baykam N. Diabetic foot infections and outcomes: a single center study. Infect Dis Clin Microbiol 2021;

2: 64-69.

DOI: 10.36519/idcm.2021.62 
swab cultures; this leads to unnecessary, inappropriate and long-term use of antibiotics. Therefore, only deep tissue biopsy culture was taken from the patients followed up with DFI in our center. In this study, the follow-up results of the patients with DFI, the cultured microorganisms from the samples obtained by tissue biopsy, and the treatment results were evaluated retrospectively.

\section{MATERIALS AND METHODS}

Our study group was adult patients over 18 years old followed up with DFI between July 26, 2015, and November 5, 2018 in the Diabetic Foot and Chronic Wound Unit of Hitit University Çorum Erol Olçok Training and Research Hospital . Patients followed up for burns and pressure ulcers were excluded from the study. Tissue cultures were taken by biopsy from intact tissue after wound debridement. Epidemiological data of the patients, Hba1c levels, nasal swab, tissue biopsy and antibiogram results of microorganisms grown in blood cultures were evaluated retrospectively. Nasal swabs and blood samples were cultured according to routine culture procedures.

Approximately $1 \mathrm{ml}$ of thioglycolate broth was added to the tissue biopsy samples and incubated at $35^{\circ} \mathrm{C}$ for 24 hours. At the end of the incubation, 1 microliter loop and a loopful sample were taken from the tube and inoculated on agar mediums such as sheep blood agar, eosin methylene blue agar, chocolate agar and sabouraud dextrose agar. Chocolate agar medium was incubated at $35-37^{\circ} \mathrm{C}$ in an environment containing 5\% CO2, while oth-

\section{HIGHLIGHTS}

- The most common gram-negative agent was Pseudomonas aeruginosa (37.1\%), and the gram-positive was Staphylococcus aureus (56.5\%).

- Tissue culturing is an important diagnostic tool that gives etiology and susceptibility pattern of bacteria in patients with DFI.

- The major amputation rate decreased from $33 \%$ to $14 \%$ within two years by the support of interdisciplinary unit. er media were incubated in an aerobic environment for 24-48 hours. Plates were evaluated daily. The first evaluation of the growing colonies was made using conventional methods (gram staining, catalase, coagulase, oxidase tests). Then, further identification of microorganisms and antibiotic susceptibility tests were performed using VITEK 2 (BioMérieux-France) automated system and VITEK 2 cards in line with the manufacturer's recommendations. Antibiotic susceptibility test results were evaluated according to EUCAST criteria (5).

Statistical analysis was performed using the Statistical Package for the Social Sciences (SPSS) for Windows, Version 16.0. Chicago, SPSS Inc; 2007. Descriptive statistics were presented as mean \pm standard deviation for normally distributed continuous data, median (min-max) for variables with asymmetrically distributed continuous data, and percentages (\%) for categorical data. The Chisquare test was used for categorical data and correlation analysis was performed if necessary between continous variables. The statistical significance was set as $\mathrm{P}<0.05$.

\section{RESULTS}

In total, 397 patients followed up with the diagnosis of DFI in the Diabetic Foot and Chronic Wound Clinic. The mean age was 65.48 (22-95) years and $74.3 \%$ of the patients were male and $96.5 \%$ (n:383) had a diagnosis of Type 2 Diabetes Mellitus (DM). Hba1c level above 7 was detected in 251 out of 343 patients (mean 8.86). In addition to DM, $65.7 \%$ of the cases had other comorbid diseases. Coronary artery disease (CAD) (35\%) and peripheral artery disease (PAD) (27.7\%) were the most common comorbidities (Table 1). The rate of the previous hospitalization was \%29.7 ( $\mathrm{n}=118)$. One hundred and eighty patients (45\%) had history of antibiotic use within the last month, and 91 (23\%) had previous history of surgery because of diabetic foot. Osteomyelitis were detected in $30.7 \%$ of the patients. The rate of fever at the time of hospital admission was 5.5\%. Among 5 out of 70 patients (17.6\%), at least one pathogen was grown in blood cultures. Escherichia coli was grown both in blood and tissue culture of one case. The other pathogens detected in blood cultures included Enterococcus faecium, Streptococcus 
Table 1. Co-morbid diseases

\begin{tabular}{|l|c|}
\hline Underlying disease & $\%(\mathrm{n})$ \\
\hline Hypertension (HT) & $36.8(146)$ \\
\hline Coronary artery disease (CAD) & $35(139)$ \\
\hline Peripheral artery disease (PAD) & $27.7(110)$ \\
\hline Chronic kidney disease (CRF) & $20.7(82)$ \\
\hline Venous insufficiency & $13.9(55)$ \\
\hline Acute kidney failure (ARF) & $7.6(30)$ \\
\hline Chronic obstructive pulmonary disease (COPD) & $6.1(24)$ \\
\hline Thyroid diseases & $3.3(13)$ \\
\hline Malignancy & $2(8)$ \\
\hline Cerebro vascular accident (CVA) & $2(8)$ \\
\hline Liver disease & $0.5(2)$ \\
\hline
\end{tabular}

HT: Hypertension; CAD: Coronary artery disease; CRF: Chronic kidney disease; COPD: Chronic obstructive pulmonary disease; CVA: Cerebro vascular accident spp., Klebsiella spp., and Stenotrophomonas maltophlia. Nasal swab cultures were obtained from 94\% (n:372) of the cases. The methicillin-sensitive Staphylococcus aureus (MSSA) was detected in eight patients (2\%), methicillin-resistant S. aureus (MRSA) was detected in four (1\%). Wagner classification was used in the evaluation of the patients. There were no patients in class 0 and class 1, 55 (13,9\%) patients in class 2, $317(79,8 \%)$ patients in class 3, 22 (5,2\%) patients in class 4 , and $3(0,8 \%)$ patients in class 5 .

Tissue biopsy cultures were obtained from the cases (n:236, 59.5\%) with open wounds with, signs of abscess or wounds requiring debridement. In other cases diagnosed with DFI according to Wagner criteria, empirical antibiotic therapy was started based on the possible microorganisms. Microbiological growth was detected in 121 (51.3\%) of the tissue cultures. A gram-negative agent was detected in 69 (57\%) of the tissue cultures, a gram-positive

Table 2. Resistance rates (\%) detected in gram-negative bacteria grown in tissue cultures.

\begin{tabular}{|l|c|c|c|c|c|c|c|}
\hline & CIP & TMP-STX & IMP & PIP-TAZ & AK & COL & TIG \\
\hline P. aeruginosa (n:26) & 52 & --- & 54 & 66 & 54 & 4 & -- \\
\hline E. coli (n:17) & 59 & 53 & 29 & 53 & 30 & 6 & 12 \\
\hline Acinetobacter spp. (n:8) & 100 & 38 & 100 & 100 & 88 & 0 & 50 \\
\hline Morganella morganii (n:8) & 75 & 50 & 0 & 0 & 13 & 76 & 38 \\
\hline
\end{tabular}

AK: Amikacin; CIP: Ciprofloxacin; COL: Colistin; IMP: Imipenem; PIP-TAZ: Piperacillin-tazobactam; TIG: Tigecycline; TMP-STX: Trimethoprim-sulphamethoxazole; R: Rezistance

Table 3. Resistance rates (\%) detected in gram-positive bacteria grown in tissue cultures.

\begin{tabular}{|l|c|c|c|c|c|c|c|}
\hline & FA & SAM & VAN & DOX & CIP & TMP-SMX & MET \\
\hline Staphylococci (n:17) & 24 & 12 & 0 & 24 & 30 & 12 & 12 \\
\hline MSSA (n:12) & 8.3 & 0 & 0 & 8.3 & 0 & 8.3 & 0 \\
\hline MRSA (n:1) & 100 & 0 & 0 & 0 & 100 & 0 & 100 \\
\hline MRCoNS (n:3) & 66.6 & 66.6 & 0 & 100 & 100 & 33.3 & 100 \\
\hline Streptococcus (n:3) & - & 0 & 0 & - & 0 & 0 & - \\
\hline Enteroccocus spp (n:3) & - & - & 0 & - & 33 & 33 & - \\
\hline
\end{tabular}

AMSSA: Methicilin sensitive Staphylococcus aureus; MRSA: Methicilin resistant Staphylococcus aureus; MRCoNS: Methicillin-resistant coagulase-negative staphylococci; FA: Fucidic acid; SAM: Ampicillin/sulbactam; VAN: Vancomycine; DOX: Doxycycline; CIP: Ciprofloxacin; TMP-STX: Trimethoprim-sulphamethoxazole 
agent in 23 (19\%), and Candida spp. in 3 (2.5\%), while polymicrobial growth was detected in 7 (5.8\%). Tissue cultures were found to be contaminated with a rate of $15.9 \%$. The most common gram-negative agent was Pseudomonas aeruginosa (37.1\%), and the gram-positive agent was S. aureus (56.5\%). MRSA did not grow in the nasal swab culture among patients whose tissue culture was positive for MRSA. Tissue culture results were detailed in table 2 and 3.

A surgical procedure was performed in 227 patients (57.2\%). Finger amputations constituted 33.5\% (n:76) of the interventions, $36.6 \%$ (n:83) were surgical debridement, the remaining 30\% (n:68) were major amputations. Our major amputation rate was 33\% in 2016, 16\% in 2017 and 14\% in 2018.

Six patients died, and the case fatality rate was $1.5 \%$ during the hospitalization. The mean duration of hospitalization was 25.45 (2-165) days.

\section{DISCUSSION}

Diabetic foot ulcers develop in approximately half of DM cases and result in amputation in 15\% (6). Most of our cases were male, and have high level of Hba1c which was consistent with the literature. The most critical condition that worsens the prognosis of diabetic foot ulcers is DFI. DFI causes a significant increase in hospitalization rate and duration, and amputation rates.

Ulcers lasting more than 30 days, peripheral artery disease (PAD), peripheral neuropathy (PN), chronic kidney disease (CKD) or a history of renal transplant, and walking barefoot are the most important risk factors for DFI (7). Consistent with the literature, $20.7 \%$ of our cases had CKD accompanying diabetes, and $27.7 \%$ had arterial embolism and ischemia.

About half of our patients had a history of antibiotic use in the last month, and 1/3 of them had a history of hospitalization. Nevertheless, we could not obtain information about previous antibiotic use.

Some studies have reported that microorganisms colonizing patients' rectal flora and nose predispose them to recurrent infections $(8,9,10)$. In addition, some studies argue that nasal MRSA carriage is an independent factor for DFI (11). Nasal carriage of MRSA was reported in $0-24.7 \%$ of diabetic patients (12). In a study from Turkey, this rate was 9.9\% (13). Nasal cultures of the patients followed up in our hospital for DFI were routinely taken. In our study, we detected 2\% nasal MSSA and 1\% MRSA carriage, but we did not detect any correlation with tissue culture. This suggests that an additional nasal swab is unnecessary and not cost-effective in patients with diabetic foot tissue culture. Rectal swab cultures were not routinely obtained.

Isolation of any microorganism in superficial swab culture has always been a matter of debate. It is not recommended to routinely take superficial swab culture because they often do not correlate with tissue culture results. Although swab cultures fail to determine the causative agent in Grade 3-4 wounds according to the Wagner classification, some studies report that it is useful in Grade 2 wounds (14). Our unit, Hitit University Çorum Erol Olçok Training and Research Hospital Diabetic Foot and Chronic Wound Clinic, is a tertiary center. Therefore, the majority of the applied cases are complicated cases (86\% cases $\geq$ Grade 3 ) who have been hospitalized in different centers before. In these cases, swab culture is not an appropriate method to detect the causative agent. A standardized collection and processing of deep tissue cultures were ideal for our center. (15). In our center, deep tissue cultures were taken from patients who had long been considered to have DFI. As a matter of fact, no growth was detected in $48.7 \%$ of our deep tissue biopsy cultures. Decreased bacterial load after surgical debridement might also have caused negative culture results. Isolation of microorganism in tissue culture was achieved among 51.3\% (n:121) of the cases whose tissue biopsy cultures were obtained. In developed countries, gram-positives are at the forefront of DFI as a factor, while in developing countries, gram-negatives are at the forefront. In our study, gram-negative agents were found in 57\% and gram-positive agents in 19\%. P. aeruginosa was the most common isolated microorganism with a rate of $21.4 \%$. P. aeruginosa is reported as a DFI agent in our country with a rate of $4-20 \%$ (16). In one study, lower-extremity amputation and previous treatment with an active wound dressing were found to be important risk 
factors for P. aeruginosa (17). Because of the use of antibiotics in approximately half of the cases we presented and the history of surgical intervention in one third, these risk factors should be questioned before starting treatment and an antibiotic with Pseudomonas spp. activity should be chosen in empirical antibiotic preference. S. aureus (56.5\%) was the leading gram-positive agent detected in deep tissue biopsy cultures. It is seen that MRSA has been reported as a factor in $18-31 \%$ of diabetic foot cases in our country in different studies (18). The rate of detection of MRSA as a causative agent in our cases $(19 \%)$ was quite low compared to these series. While methicillin resistance in coagulase-negative staphylococci (CoNS) has been reported as $71-79 \%$ in different studies (19), methicillin resistance was detected at a rate of $100 \%$ in our cases. For this reason, methicillin resistance was taken into account in an empirical treatment regimen involving gram-positive microorganisms in our centre.

It is a known fact that DFI-related amputation rates are quite high in tertiary hospitals following DFI. A meta-analysis reported an amputation rate of $30.5 \%$ at any level. Most of the cases transferred from different centers were severe, complicated cases accompanied by osteomyelitis and peripheral vascular disease. Male gender, history of amputation-osteomyelitis, presence of PAD, Wagner class 4 and 5, gangrene/necrosis, neuro-ischemic ulcer, severe infection, long hospital stay, increase in acute phase reactants, growth of gram-negative agents in tissue biopsy culture are detected risk factors for lower extremity amputation (20). In our cases, the excess of male patients (74.3\%), previous surgical intervention $(22.9 \%)$, PAD $(27.7 \%)$, presence of osteomyelitis (30.7\%) and gram-negative weight of microorganisms grown in tissue biopsy cultures were important risk factors that predispose to amputation, in line with the literature. In the years when our centre was first established, the rate of major amputation was high. In the literature, there are studies on the reduction of major amputation rates with interdisciplinary teamwork (21). It was observed that the major amputation rate of our patients, who were followed up with an interdisciplinary approach rather than a multidisciplinary approach, together with the diabetic foot council actively working in our hospital, decreased over time and was lower than the literature data.

In a study in which DFI-related mortality was 3\%, ischemic wound, infection in the posterior foot region, infection involving the whole foot, PAD, high leukocyte levels, high platelet levels, high CRP, and polymicrobial growth in deep tissue culture were reported as important parameters in predicting mortality (18). In our center, the mortality rate (1.5\%) was quite low. Due to our low mortality rate, a statistically significant evaluation could not be made. However, the cause of death was not uncontrolled DFI or sepsis, but other complications of diabetes or cardiac diseases.

\section{CONCLUSION}

As a result, treatment of DFIs is a long-term problem that requires serious patience and effort. It is important to determine the causative microorganism and the sensitivity pattern correctly. Therefore, the importance of tissue biopsy cultures is increasing. Since it is possible to detect the microorganism with tissue biopsy culture taken at the appropriate time, nasal and rectal colonization cultures are no longer important. Nasal and rectal swab cultures can only guide cases of osteomyelitis, which are deep and difficult to sample. Apart from this, nasal swab cultures are no longer routinely taken in our center due to loss of workforce and additional cost. It is also clearly seen that the major amputation rates have decreased in DFI followed by an interdisciplinary approach.

In the context of the country, it is necessary to increase the centers dealing with DF wounds and focus on studies to prevent DFI. 
Ethical Approval: Ethical Committee of Hitit University approved the study on January 6, 2021 with the decision number of 381 .

Informed Consent: This is a retrospective study for which no formal consent is required.

Peer-review: Externally peer-reviewed

Author Contributions: Concept - D.Y., Ö.A., M.K., A.K.Ç., N.B.; Design - D.Y., Ö.A., M.K., A.K.C.., N.B.; Supervision - D.Y., Ö.A., M.K., A.K.Ç., N.B.; Funding - D.Y., Ö.A., M.K., A.K.Ç.; Materials - D.Y.,
Ö.A., M.K., A.K.Ç.; Data Collection and/or Processing - D.Y., Ö.A., M.K., A.K.Ç.; Analysis and/or Interpretation - D.Y., Ö.A., A.K.Ç.; Literature Review - D.Y., Ö.A., A.K.Ç.; Writer - D.Y., Ö.A., A.K.Ç., N.B., M.K.; Critical Reviews - D.Y., Ö.A., M.K., A.K.Ç., N.B.

Conflict of Interest: The authors have no conflict of interest to declare.

Financial Disclosure: The authors declared that this study has received no financial support.

\section{REFERENCES}

1 Lipsky BA, Berendt AR, Embil J, De Lalla F. Diagnosing and treating diabetic foot infections. Diabetes Metab Res Rev. MayJun, 2004;20 Suppl 1:S56-64. [CrossRef]

2 Pickwell K, Siersma V, Kars M, Apelqvist J, Bakker K, Edmonds $\mathrm{M}$, et al. Predictors of lower-extremity amputation in patients with an infected diabetic foot ulcer. Diabetes Care. May, 2015;38(5):852-7. [CrossRef]

3 Jia L, Parker CN, Parker TJ, Kinnear EM, Derhy PH, Alvarado AM, et al. Diabetic Foot Working Group, Queensland Statewide Diabetes Clinical Network (Australia). Incidence and risk factors for developing infection in patients presenting with uninfected diabetic foot ulcers. PLoS One. May 17, 2017;12(5):e0177916. [CrossRef]

4 Shahbazian H, Yazdanpanah L, Latifi SM. Risk assessment of patients with diabetes for foot ulcers according to risk classification consensus of international working group on diabetic foot (IWGDF). 2013;29(3):730-734. [CrossRef]

5 European Committee on Antimicrobial Susceptibility Testing. Breakpoint tables for interpretation of MICs and zone diam eters [Internet]. EUCAST. (cited August 22, 2021). Available from: https://www.eucast.org/ast_of_bacteria/previous_versions of documents/

6 Lazzarini PA, Hurn SE, Fernando ME, Jen SD, Kuys SS, Kamp $\mathrm{MC}$, et al. Prevalence of foot disease and risk factors in general inpatient populations: a systematic review and meta-analysis. BMJ Open. 2015;5(11):e008544. [CrossRef]

7 Nikoloudi M, Eleftheriadou I, Tentolouris A, Kosta OA, Tentolouris N. Diabetic Foot Infections: Update on Management. Curr Infect Dis Rep. Aug 1, 2018;20(10):40. [CrossRef]

8 Smith K, Collier A, Townsend EM, O'Donnell LE, Bal AM, Butch er J, et al. One step closer to understanding the role of bacteria in diabetic foot ulcers: characterising the microbiome of ulcers. BMC Microbiol. Mar 22, 2016;16:54. [CrossRef]

9 Van Asten SA, La Fontaine J, Peters EJ, Bhavan K, Kim PJ, Lavery LA. The microbiome of diabetic foot osteomyelitis. Eur J Clin Microbiol Infect Dis. Feb, 2016;35(2):293-8. [CrossRef]

10 Lavery LA, Fontaine JL, Bhavan K, Kim PJ, Williams JR, Hunt NA Risk factors for methicillin-resistant Staphylococcus aureus in diabetic foot infections. Diabet Foot Ankle. Apr 10, 2014. [CrossRef]

11 Lin SY, Lin NY, Huang YY, Hsieh CC, Huang YC. Methicillin-resistant Staphylococcus aureus nasal carriage and infection among patients with diabetic foot ulcer. J Microbiol Immunol Infect. Apr, 2020;53(2):292-9. [CrossRef]
12 Alizargar J, Sharif M, Sharif A. Risk factors of methicillin-resistant Staphylococcus aureus colonization in diabetic outpatients, a prospective cohort study department of pediatrics and infectious disease, Kashan University of Medical Sciences, Kashan, Iran. International Journal of Microbiological Research. 2013;4 (2):147-51.

13 Kutlu SS, Cevahir N, Akalin S, Akin F, Dirgen Caylak S, Bastemir $\mathrm{M}$, et al. Prevalence and risk factors for methicillin-resistant Staphylococcus aureus colonization in a diabetic outpatient population: a prospective cohort study. Am J Infect Control. May, 2012;40(4):365-8. [CrossRef]

14 Huang Y, Cao Y, Zou M, Luo X, Jiang Y, Xue Y, et al. Comparison of tissue versus swab culturing of infected diabetic foot wounds. Int J Endocrinol. 2016;2016:8198714. [CrossRef]

15 Lipsky BA, Aragón-Sánchez J, Diggle M, Embil J, Kono S, Lavery L, International Working Group on the Diabetic Foot, et al. IWGDF guidance on the diagnosis and management of foot infections in persons with diabetes. Diabetes Metab Res Rev. Jan, 2016;32 Suppl 1:45-74. [CrossRef]

16 Saltoğlu N, Kılıçoğlu Ö, Baktıroğlu S, Oşar-Siva Z, Aktaş Ş, Altındaş $\mathrm{M}$, et. al. Diyabetik ayak yarası ve infeksiyonunun tanısı, tedavisi ve önlenmesi: Ulusal uzlaşı raporu. Klimik Derg. 2015.28(Suppl 1), 2-34. Turkish.

17 Ertugrul BM, Lipsky BA, Ture M, Sakarya S. Risk Factors for Infection with Pseudomonas aeruginosa in Diabetic Foot Infections. J Am Podiatr Med Assoc. Nov, 2017;107(6):483-489. [CrossRef]

18 Saltoglu N, Ergonul O, Tulek N, Yemisen M, Kadanali A, Karagoz $\mathrm{G}$, et al. Turkish Society of Clinical Microbiology and Infectious Diseases, Diabetic Foot Infections Study Group. Influence of multidrug resistant organisms on the outcome of diabetic foot infection. Int J Infect Dis. May, 2018;70:10-14. [CrossRef]

19 Utlu Y, Başak O, Bozkurt-Kozan F, Ertuğrul MB. Causative agents and factors associated with multidrug resistant pathogens in diabetic foot infections. Klimik Derg. 2019;32(1):84-9. Turkish. [CrossRef]

20 Sen P, Demirdal T. Evaluation of mortality risk factors in diabetic foot infections. Int Wound J. Aug, 2020;17(4):880-9. [CrossRef]

21 Martínez-Gómez DA, Moreno-Carrillo MA, Campillo-Soto A, Carrillo-García A, Aguayo-Albasini JL. Reduction in diabetic amputations over 15 years in a defined Spain population. Benefits of a critical pathway approach and multidisciplinary team work. Rev Esp Quimioter. Sep, 2014;27(3):170-9. 